Department of Health (2002) Seeking Consent: Working with People in Prison. London: Department of Health.

Earthrowl, M., O'Grady, J. \& Birmingham, L. (2003) Providing treatment to prisoners with mental disorders: development of a policy. Selective literature review and expert consultation exercise. British Journal of Psychiatry I82, 299-302.

L. Birmingham, J. O'Grady University of Southampton School of Medicine, Community Clinical Sciences Research Division, Ravenswood House, Medium Secure Unit, Knowle, Fareham, Hampshire POI7 5NA, UK

\section{Amisulpride-induced mania in a patient with schizophrenia}

Numerous case reports of atypical antipsychotics inducing hypomanic/manic symptoms have been published; most concern the use of risperidone and olanzapine (Aubry et al, 2000), but quetiapine (Benazzi, 2001) and ziprasidone (Lu et al, 2002) have also been implicated. A literature search using Medline and PubMed revealed no such reports associated with amisulpride. Although the manufacturer has accumulated a small number of reports of manic symptoms developing during amisulpride treatment, a recent internal review concluded that no causality could be established (Sanofi-Synthelabo, personal communication, 2002). I report a case of amisulpride-induced mania.

A 17-year-old female with a 4-year history of schizophrenia was commenced on amisulpride for persistent negative symptoms. It was cross-titrated with olanzapine, over a 4-week period, to $400 \mathrm{mg}$. She continued taking citalopram $20 \mathrm{mg}$, which had been started 6 months previously on the basis that her negative symptoms could be secondary to a masked depression. On commencement of amisulpride her negative symptoms, as rated on the Scale for the Assessment of Negative Symptoms (SANS; Andreasen, 1982), rapidly and linearly improved. Her mood, however, continued to rise and by 3 months she had developed a manic episode without psychotic features. She exhibited insomnia, hyperactivity, distractibility, disinhibition and an abnormally and persistently elevated mood that continued despite the immediate cessation of citalopram. There was no evidence of substance misuse or akathisia. These features improved after halving the amisulpride to $200 \mathrm{mg}$ and re-introducing olanzapine $15 \mathrm{mg}$. They fully remitted within days of stopping the amisulpride.
No other concomitant medication was used. The delay in development of overt manic symptoms may reflect having to overcome a baseline SANS score of 68 .

The mechanism of action of mood changes induced by atypical antipsychotics is unknown, with speculation centring exclusively on a $5-\mathrm{HT}_{2 \mathrm{a}}: \mathrm{D}_{2}$ economy. Lane et al (1998) argue that a higher ratio will increase frontal dopamine release, whereas others point to the combined blockade enhancing the ability of $5-\mathrm{HT}_{1 \mathrm{a}}$ to release frontal dopamine (Ichikawa et al, 2001). These theories do not explain the manicogenic effects of amisulpride, which has no serotonin affinity. I propose that the ability of low doses of amisulpride to differentially block presynaptic $\mathrm{D}_{2}$ and $\mathrm{D}_{3}$ autoreceptors enhances dopamine transmission in the frontal cortex and can lead to the development of manic symptoms in susceptible subjects. Presumably this mechanism contributes to its antidepressant efficacy, for which it is used in many countries. The theory implies induction of manic features at low doses only.

\section{Declaration of interest}

B.P.M. works for ORYGEN, which has received an unrestricted educational grant from Sanofi-Synthelabo.

Andreasen, N. C. (1982) The Scale for the Assessment of Negative Symptoms. lowa, IA: University of lowa.

Aubry, J.-M., Simon, A. E. \& Bertschy, G. (2000)

Possible induction of mania and hypomania by olanzapine and risperidone: a critical review of reported cases. Journal of Clinical Psychiatry, 61, 649-65I.

Benazzi, F. (200I) Quetiapine-associated hypomania in a woman with schizoaffective disorder. Canadian Journa of Psychiatry, 46, 182-183.

Ichikawa, J., Ishii, H., Bonaccorso, S., et al (200I) $5-\mathrm{HT}_{2}$ and $\mathrm{D}_{2}$ receptor blockade increases cortical $\mathrm{DA}$ release via $5-\mathrm{HT}_{\mathrm{la}}$ receptor activation: a possible mechanism of action of atypical antipsychotic-induced cortical dopamine release. Journal of Neurochemistry, $\mathbf{7 6}$ |52|-|53|.

Lane, H. Y., Lin, Y. C. \& Chang, W. H. (1998) Mania induced by risperidone: dose related? Journal of Clinical Psychiatry, 59, 85-86.

Lu, B. Y., Lundgren, R., Escalona, P. R., et al (2002)

A case of ziprasidone-induced mania and the role of $5-\mathrm{HT}_{2 \mathrm{a}}$ in mood changes induced by atypical antipsychotics. Journal of Clinical Psychiatry, 63, ||85-||86.

B. P. Murphy Early Psychosis Prevention and Intervention Centre, ORYGEN Youth Health, Locked Bay 10 (35 Poplar Road), Parkville, Victoria, Australia 3052

\section{Changing use of ECT}

I would like to point out a couple of facts about the decline in electroconvulsive therapy (ECT) use not mentioned by Eranti \& McLoughlin (2003) in their recent editorial.

The use of ECT without consent has not declined at all since 1985 . There were 3362 people given ECT without their consent under section 58 of the Mental Health Act 1983 in England and Wales in the 2year period 1985-87, 4454 in 1987-89 and 4463 in 1999-2001, with little change in the years between (Mental Health Act Commission, 1988-2002).

It was the 1970s that saw the greatest decline in ECT use, from an estimated 60000 courses in Great Britain in 1972 to 30000 in 1979 (Pippard \& Ellam, 1981).

The decline in ECT use over the past 20 years or so has been marked by regional variations. While in England ECT use fell fairly steadily during the 1980s, in Scotland it remained fairly constant during the 1980s and early 1990s and then fell by about a half in the mid-1990s (Freeman et al, 2000). In the East Anglian region ECT use actually increased during the 1980s (Pippard, 1992).

I think it is hard to reconcile these facts with the authors' suggestion that new drugs, improvements in patient care and better appreciation of the indications for ECT are responsible for the decline in ECT; although this would be the most respectable explanation for the decline in use of a treatment which is still described as safe, effective and life-saving - especially since the textbook indications for its use have changed little over the past two or three decades. Is it really the case that fewer people need ECT nowadays - or was it given needlessly to large numbers of people in the recent past? Since no research into the reasons for the decline in the use of ECT has been done, it remains impossible to answer this question with any certainty.

Eranti, S. V. \& McLoughlin, D. M. (2003)

Electroconvulsive therapy - state of the art. British Journal of Psychiatry, 182, 8-9.

Freeman, C. P. L., Hendry, J. \& Fergusson, G. (2000) National Audit of Electroconvulsive Therapy in Scotland. Edinburgh: Scottish Office.

Mental Health Act Commission (1988-2002) Biennia Reports (2nd to 9th). London: Stationery Office.

Pippard, J. (1992) Audit of electroconvulsive treatment in two National Health Service regions. British Journal of Psychiatry, 160, 621-637.

- \& Ellam, L. (1981) Electroconvulsive Treatment in Great Britain 1980. London: Gaskell.

S. Kemsley Address supplied; correspondence c/o the British Journal of Psychiatry, 17 Belgrave Square, London SWIX 8PG, UK 